\title{
Eyewear for Rugby Union: Wearer Characteristics and Experience with Rugby Goggles
}

\section{()(1) $\odot \Theta$}

Authors

Julie-Anne Little ${ }^{1}$ D, Fabienne Eckert ${ }^{1}$, Marc Douglas ${ }^{2}$, Brendan T. Barrett ${ }^{3}$

\section{Affiliations}

1 Centre for Optometry \& Vision Science, University of Ulster, Coleraine, United Kingdom of Great Britain and Northern Ireland

2 World Rugby, Technical Services, Dublin, Ireland

3 School of Optometry and Vision Science, University of Bradford, Bradford, United Kingdom of Great Britain and Northern Ireland

\section{Key word}

rugby, goggles, eye injury, spectacles, monocular, visual impairment

accepted $\quad 14.11 .2019$

Bibliography

DOI https://doi.org/10.1055/a-1068-9501

Published online: 27.1.2020

Int J Sports Med 2020; 41: 311-317

(c) Georg Thieme Verlag KG Stuttgart · New York

ISSN 0172-4622

\section{Correspondence}

Dr. Julie-Anne Little

Centre for Optometry \& Vision Science

Biomedical Sciences, University of Ulster

BT52 1SA Coleraine

United Kingdom of Great Britain and Northern Ireland

Tel : 02870124374 , Fax : 02870124374

ja.little@ulster.ac.uk

\begin{abstract}
Unlike many other sports, Rugby Union has not permitted players to wear spectacles or eye protection. With an industrial partner, World Rugby developed goggles suitable for use while playing rugby for the purposes of growing participation amongst those that need to wear corrective lenses. This study reports on the profile and experiences of goggle wearers. 387 players received the goggles. Data were obtained from 188 (49\%) using an online, 75 -item questionnaire. $87 \%$ "strongly agreed/agreed" that goggles are beneficial and $75 \%$ are happy with goggle performance. Common problems reported by 49.7 and $32.6 \%$ of respondents were issues with fogging-up and getting dirty. 15 (8\%) players stopped wearing the goggles because of fogging-up, limits to peripheral vision and poor comfort/fit. Injuries were reported in $3 \%$ of respondents. In none of these cases did the player stop wearing the goggles. From the positive experience of players in the trial, the goggles were adopted into the Laws of the game on July 1, 2019. As the need to correct vision with spectacles is common, and contact lenses are not worn by $80 \%+$ of spectacle wearers, the new Rugby goggles will widen participation for those that need to wear refractive correction, or have an existing/increased risk of uniocular visual impairment.
\end{abstract}

\section{Introduction}

Sport is a significant cause of eye injury. The proportion of new eye injuries presenting to hospital that are sports-related range from $12.9 \%$ [1] to $40 \%$ [2]. Also, when they arise, sports-related eye injuries are often serious. In the UK, for example, $12.5 \%$ to $25-40 \%$ of sports-related eye injuries are severe enough to require hospital admittance [3,4]. Furthermore, $11 \%$ of cases of presenting to hospital with sport-related eye injury cause permanent visual disability [1] and in the USA, sport may account for almost one-third of eye injuries that lead to blindness [5].

Cass [6] suggests that $~ 90 \%$ of all sports-related eye injuries can be prevented with adequate eye protection, a view shared by sev- eral other authors [4-7]. Protective eyewear is now available for a large range of sports [8] and is mandatory in several sports (e.g., ice hockey [1]). There is evidence that the increased use of protective eyewear has reduced the incidence of eye injuries in certain sports (e. g., field hockey [9], ice-hockey [10], and squash [11]).

The need for optical correction of refractive errors of the eye is common, with over $50 \%$ of the adult population in Europe [12], and $32 \%$ children [13] requiring refractive correction by spectacles or contact lenses in order to see clearly.

Rugby Union is played in 121 countries with $~ 8.5$ million players worldwide [14]. In many sports, there is a safety risk from wearing spectacles in terms of breakage and injury from the spectacles 
(both for the wearer and other players), and in Rugby Union, spectacles are not permitted under World Rugby Laws 4.5c [15]. This impacts those who cannot wear contact lenses, have an increased risk of potential for ocular damage (e. g., history of retinal detachment, post-LASIK surgery), have a visual impairment, or are blind in one eye (e. g., amblyopia, past injury) and who do not wish to risk the sight of their remaining eye. Individuals with uniocular visual impairment are particularly encouraged to wear eye protection when participating in high-risk sports [16].

Recognizing that certain individuals would not be able to play the game because of the lack of suitable eyewear, World Rugby, the global governing body for the laws of Rugby Union, teamed up with a manufacturer to produce goggles suitable for use while playing rugby [17]. The primary aim of introducing the goggles was to enable corrective lenses to be worn on the field by those unable to wear contact lenses, as opposed to developing protective equipment. The first version of these goggles (Rugby Goggles 1.0) was piloted in 2013. In 2017, an updated version was produced (Rugby Goggles 2.0). Before deciding whether the goggles could be added to the laws of the game, World Rugby commissioned a trial to assess the performance and suitability for play of the goggles from the wearer's perspective. The present study reports the results from this trial (full report available [18]). Fig. 1 is a photograph of the rugby goggle worn during an international match.

\section{Materials and Methods}

Unlike the first version, Rugby Goggles 2.0 is made available in two sizes, with a new smaller size goggle being produced. The study was conducted in accordance with international ethical standards for sport and exercise science research [19], received ethical approval from the University Research Ethics Committee, and started in August 2017.

Participants who had purchased Rugby Goggles 1.0 were invited to take part in the trial of Rugby Goggles 2.0. They are referred to as Category A participants and they were offered the Rugby Goggles 2.0 free of charge between August 2017 and January 2018.

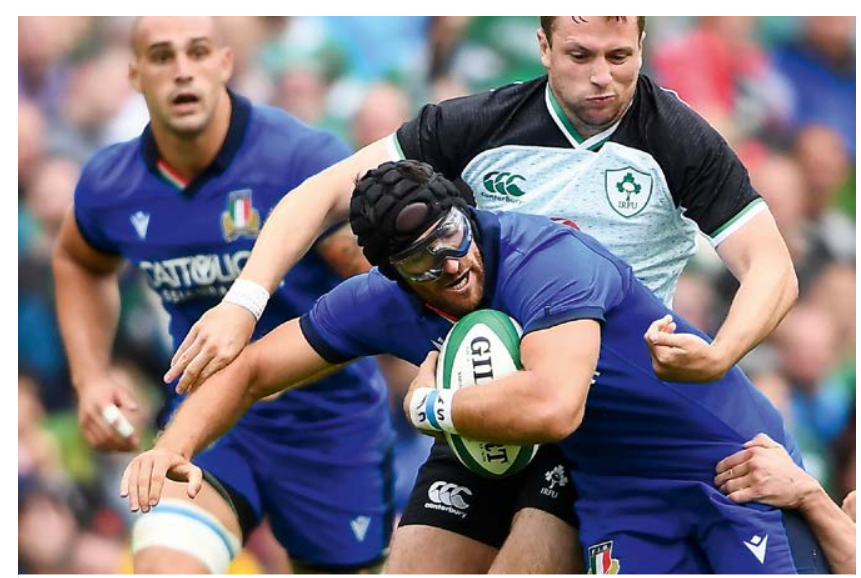

- Fig. 1 Rugby Goggles worn during international match play by lan McKinley. Italy vs. Ireland; August 10, 2019. Photograph credit: Federazione Italiana Rugby.
Participants who had previously expressed an interest in, but who did not purchase, the goggles previously were invited to purchase the Rugby Goggles 2.0 directly from the manufacturer (Raleri) and to take part in this trial. World Rugby issued a press release and tweets to raise awareness of the trial. Any individual affiliated with a Union participating in the trial was permitted to sign up via the World Rugby website and to purchase Rugby Goggles 2.0 directly from Raleri. Participants who received goggles for the first time are referred to as Category B participants.

All trial participants received a unique purchase code from World Rugby, which anonymised the data they provided while ensuring the authenticity of the responses because only those who had received Rugby Goggles 2.0 were eligible to provide feedback.

An online questionnaire (available as Supplementary Material) was developed to request detailed information on participants' experiences of using Rugby Goggles 2.0. The questionnaire contained 75 items relating to goggles wear including getting used to the goggles, comfort, fit, field of vision, fogging, dirtying, suitability in different weather conditions, ease of cleaning, scratching, strap performance, foam performance, and use of the prescription insert. Items were answered through a checklist of options, a fivepoint Likert scale, and free text responses. The questionnaire also asked about any injuries that took place to the wearer or another player as a result of wearing the goggles.

The questionnaire was available from June to September 2018. In the case of children, a parent or guardian was permitted to complete the questionnaire. The online questionnaire was made available to participants in four languages: English, French, Spanish, and Italian.

\section{Results}

\section{Questionnaire response rate}

Of the 387 people who received a pair of Rugby Goggles 2.0 in the time frame of the study, questionnaire data were obtained from 188 (49\%) participants, hereafter called the 'respondents'. Of the 188 respondents, 129 (69\%) were category A participants and $31 \%$ were category $B$ participants.

Comparing the profile of participants who signed up for the trial but who did not complete the questionnaire to those that did, the respondents were representative of the overall cohort of individuals in terms of age, gender, and level of rugby played (one-way ANOVA, all $p>0.05$ ).

Twenty-three Rugby Unions took part in the trial. The Federazione Italiana Rugby and the Irish Rugby Football Union had the most respondents $(n=34$ [18.1\%] and 33 [17.6\%] respondents, respectively), followed by the Fédération Française de Rugby ( $n=23$ [15\%]), the USA Rugby Football Union ( $n=15$ [8\%]), and the Welsh Rugby Union ( $n=14$ [7.4\%]).

\section{Characteristics of respondents and pattern of goggle wear}

- Table 1 summarizes the characteristics of respondents and aspects of goggles wear. The most commonly reported age range for respondents was under 14 years ( $45 \%$ ), and $68 \%$ of respondents 
were under the age of 18 years. Of the 188 responses, 11 were female (6\%).

Respondents were asked about their reason(s) for wearing the goggles. The majority of respondents reported that they wear the goggles because they normally need to wear glasses or contact lenses to correct their vision (70\%). Limited useful vision in one eye was indicated by $15 \%$ as the primary reason for wearing the goggles, and an additional eight (4.3\%) respondents chose this as a secondary option. Concern about the risk of injury was given as a primary reason by 7 respondents (4\%), and an additional 15 (8.0\%) chose this as a secondary option. Thirteen respondents (7\%) reported 'other' reasons, which included ocular disease (e. g., corneal disease), previous injury to eye (e. g., retinal detachment and wear of a prosthetic eye).

The majority of respondents reported that they played non-contact, under-age rugby (65\%), followed by community adult rugby ( $23 \%$ ). The larger goggles were selected by $82 \%$ of respondents and only $18 \%$ the small goggles. Of those under $14,76 \%$ chose the larger goggle size.

The majority ( $61 \%$ ) of participants reported having worn the goggles in at least 20 games or training sessions.

\section{Injuries}

Respondents were asked about injuries that had occurred as a result of goggles wear. Although we cannot be certain that the injuries would not have arisen in the absence of the goggles, our assumption is that they were caused by goggles wear. Of the five injuries reported ( $3 \%$ of respondents), four were to the person wearing the goggles and one was to an opponent. The body areas injured were: cheekbones, nose, above the nose between the eyebrows, and eye. Injuries mostly consisted of bruising and cutting of the skin on or near the nose. Medical assistance was required on the pitch in two cases and in hospital in one case. Those who reported injury were male and were represented across the age ranges.

In only one case was poor visibility through the goggles mentioned as a possible cause. The description of the injuries appeared to indicate that they had resulted from the goggles pressing onto the face following a tackle. Problems with the foam (i. e., becoming detached, not absorbing the impact) were mentioned in three out of five cases of injury. Despite the injuries, there were no cases where the injured players decided to stop playing rugby altogether or to continue playing rugby without the goggles.

\section{Adjusting to the goggles}

For the $27 \%$ of respondents ( $n=51)$ who reported they had not fully adjusted to the goggles, ( $\triangleright$ Table $\mathbf{1}$ ), the main reasons given were the limited vision due to fogging of the goggles and the limited field of view. Of these respondents, 30 (59\%) felt that they would adjust in time, but $15(29 \%)$ reported that they had stopped wearing the goggles. Thus 15 of 188 (8\%) 'failed' with the goggles to the point that they gave up wearing them because they were not able to get used to playing in them.

\section{Fogging, dirt, and weather}

Three important areas are highlighted in $>$ Fig. 2 . They concern the goggles fogging, getting dirty, and being unsuitable for all weath-
- Table 1 Characteristics of respondents and reasons and duration of Rugby Goggle wear.

\begin{tabular}{|c|c|c|}
\hline & Response Categories & Number (\%) \\
\hline \multirow[t]{7}{*}{ Age } & Under 14 years & $84(44.7 \%)$ \\
\hline & $14-18$ years & $43(22.9 \%)$ \\
\hline & $19-23$ years & $9(4.8 \%)$ \\
\hline & $24-30$ years & $20(10.6 \%)$ \\
\hline & $31-40$ years & $18(9.6 \%)$ \\
\hline & $41-50$ years & $10(5.3 \%)$ \\
\hline & $50+$ years & $4(2.1 \%)$ \\
\hline \multirow[t]{2}{*}{ Gender } & Male & $177(94.1 \%)$ \\
\hline & Female & $11(5.9 \%)$ \\
\hline \multirow[t]{5}{*}{$\begin{array}{l}\text { Reasons for } \\
\text { wearing goggles } \\
\text { (primary choice) }\end{array}$} & $\begin{array}{l}\text { - Normally need to wear glasses or } \\
\text { contact lenses to correct your } \\
\text { vision (e.g., for long- or } \\
\text { short-sightedness); }\end{array}$ & $132(70.2 \%)$ \\
\hline & $\begin{array}{l}\text { - Limited useful vision in one eye } \\
\text { (i. e., due to accident or disease); }\end{array}$ & $28(14.9 \%)$ \\
\hline & - Unable to wear contact lenses; & $8(4.3 \%)$ \\
\hline & $\begin{array}{l}\text { - Concerned about the risk of } \\
\text { injury; }\end{array}$ & $7(3.7 \%)$ \\
\hline & - Other reasons & $13(6.9 \%)$ \\
\hline \multirow{6}{*}{$\begin{array}{l}\text { Level of rugby } \\
\text { played }\end{array}$} & Elite & $5(2.7 \%)$ \\
\hline & Sub-elite & $12(6.4 \%)$ \\
\hline & Community (adult) & $44(23.4 \%)$ \\
\hline & Under-age & $122(64.9 \%)$ \\
\hline & Non-contact under-age & $4(2.1 \%)$ \\
\hline & Tag and Touch & $1(0.5 \%)$ \\
\hline \multirow{2}{*}{$\begin{array}{l}\text { Goggle size } \\
\text { chosen }\end{array}$} & Regular & $154(82 \%)$ \\
\hline & Small & $34(18 \%)$ \\
\hline \multirow{2}{*}{$\begin{array}{l}\text { Length of time } \\
\text { wearing goggles }\end{array}$} & 2-6 months & $(83 \%)$ \\
\hline & 6 months + & $(16 \%)$ \\
\hline \multirow{5}{*}{$\begin{array}{l}\text { Number of } \\
\text { games/training } \\
\text { sessions played } \\
\text { with goggles }\end{array}$} & $1-4$ sessions & $10(5.3 \%)$ \\
\hline & $5-10$ sessions & $15(8.0 \%)$ \\
\hline & $11-20$ sessions & $23(12.3 \%)$ \\
\hline & $20+$ sessions & $115(61.5 \%)$ \\
\hline & Other & $24(12.8 \%)$ \\
\hline \multirow{5}{*}{$\begin{array}{l}\text { How many } \\
\text { games/training } \\
\text { sessions did it } \\
\text { take to get used } \\
\text { to goggles }\end{array}$} & $1-2$ sessions & $56(41.2 \%)$ \\
\hline & 3-6 sessions & $61(44.9 \%)$ \\
\hline & $7-10$ sessions & $10(7.4 \%)$ \\
\hline & $11-15$ sessions & $4(2.9 \%)$ \\
\hline & $15+$ sessions & $5(3.7 \%)$ \\
\hline \multirow{3}{*}{$\begin{array}{l}\text { Are respondents } \\
\text { used to wearing } \\
\text { goggles }\end{array}$} & Yes & $73 \%$ \\
\hline & No & $8 \%$ \\
\hline & Partially & $19 \%$ \\
\hline
\end{tabular}

er conditions. For these three statements, the majority of respondents had a negative or neutral response, indicating that problems were noted in relation to these issues. In particular, respondents reported dissatisfaction with the fogging of the goggles (49.7\%) and their suitability for all weather conditions (34.7\% negative). In terms of getting dirty, $32.6 \%$ saw this is an issue. 


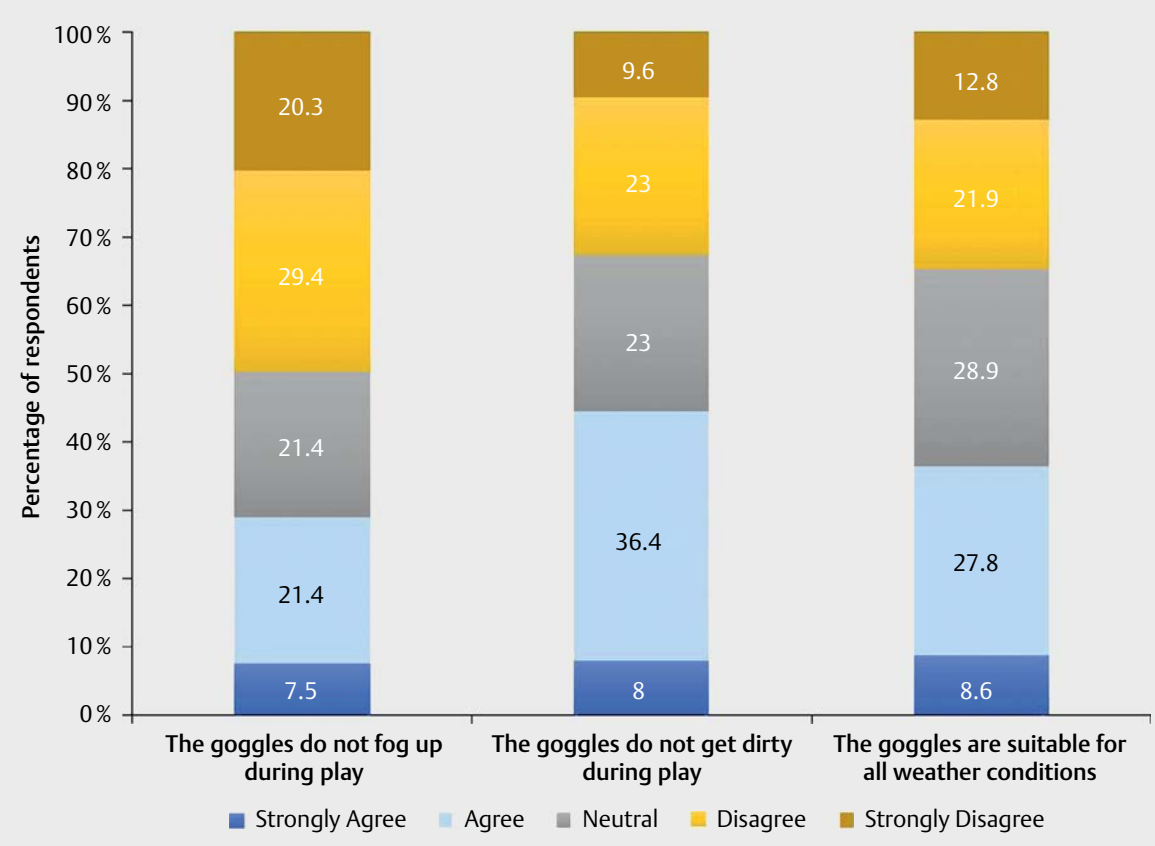

Fig. 2 Responses to statements regarding the goggles' fogging, getting dirty, and their suitability in all weather conditions. ( $n=187)$.

A follow-up question was asked regarding the issue of fogging, with $n=149$ respondents. The majority consider fogging of the goggles to be a significant issue, with $63.8 \%$ responding negatively or neutrally. Some reported they could not use the goggles when they were fogged and the fog that forms in between the outer screen and the optical insert is difficult to clear. Respondents noted, in particular, that fogging happens in cold and or humid weather conditions and owing to perspiration.

\section{Prescription insert}

A total of $73 \%$ ( $n=137)$ of respondents reported wearing the goggles with the optical insert. The majority $(81 \%)$ reported that it was "easy" or "very easy" to have the insert glazed. Those who raised concerns mentioned that it was difficult to find an optician who could prepare the insert. Others reported they had difficulty fitting or removing the insert due to the 'delicate attachment mechanism', and that the insert is easily dislodged from its position. When respondents were asked whether the optical insert had ever become dislodged while wearing the goggles during play, $14 \%(n=19$ of 137 ) reported that it had. A total of $32 \%$ of respondents reported problems with the insert mainly due to fogging issues between the outer screen and the insert.

\section{The strap and foam padding}

The vast majority $(87 \%, n=160)$ of respondents did not report any problems with the strap. Of those who $\operatorname{did}(13 \%, n=23)$, comments included that the grip and fit were compromised especially from sweat and dirt adhering to the strap. A substantial proportion ( $40 \%$, $n=73$ ) of respondents reported problems with the foam padding, in particular indicating that the foam became detached and worn out, especially owing to rain and sweat. In a number of instances, $(n=19$, $10 \%$ ), they reported they had to replace or re-glue the foam padding.

\section{Stability of goggles on the face}

While $68 \%(n=125)$ of respondents agreed that 'the goggles remain well placed, have not come off or been dislodged', $23 \%$ $(n=42)$ reported that they had been dislodged during play, and in $9 \%$ of wearers $(n=16)$, the goggles had come off altogether. Respondents also noted that the goggles were slippery because of sweat and poor strap performance, which contributed to them moving easily.

\section{Scratching}

Respondents were asked if the surface or insert of the goggles had become scratched, and $48 \%$ respondents said that this was the case. The vast majority of respondents reported that this occurred on the outside surface of the lens and that it occurred during play. Comments from respondents confirmed that the majority ( $80 \%$ ) of scratches happened during play. However, some also reported that the cleaning process and improper storage played a role as well, as did the contact/friction between the insert and outer screen.

\section{Overall performance of the goggles}

- Fig. 3 shows that overall the majority of respondents are satisfied with the performance of the goggles when it came to comfort, fit, vision and the field of vision. In all cases, the majority of respondents reported that they either "agreed" or "strongly agreed" with the statements shown at the top of the panels in $>$ Fig. 3. However, of note is that field of vision was an issue for $16.0 \%$ of respondents and $10.7 \%$ were not satisfied with their vision while wearing the goggles.

- Figure 4 summarizes a series of responses relating to respondents' overall satisfaction with the goggles, and demonstrates mainly high levels of satisfaction. The majority of respondents reported 


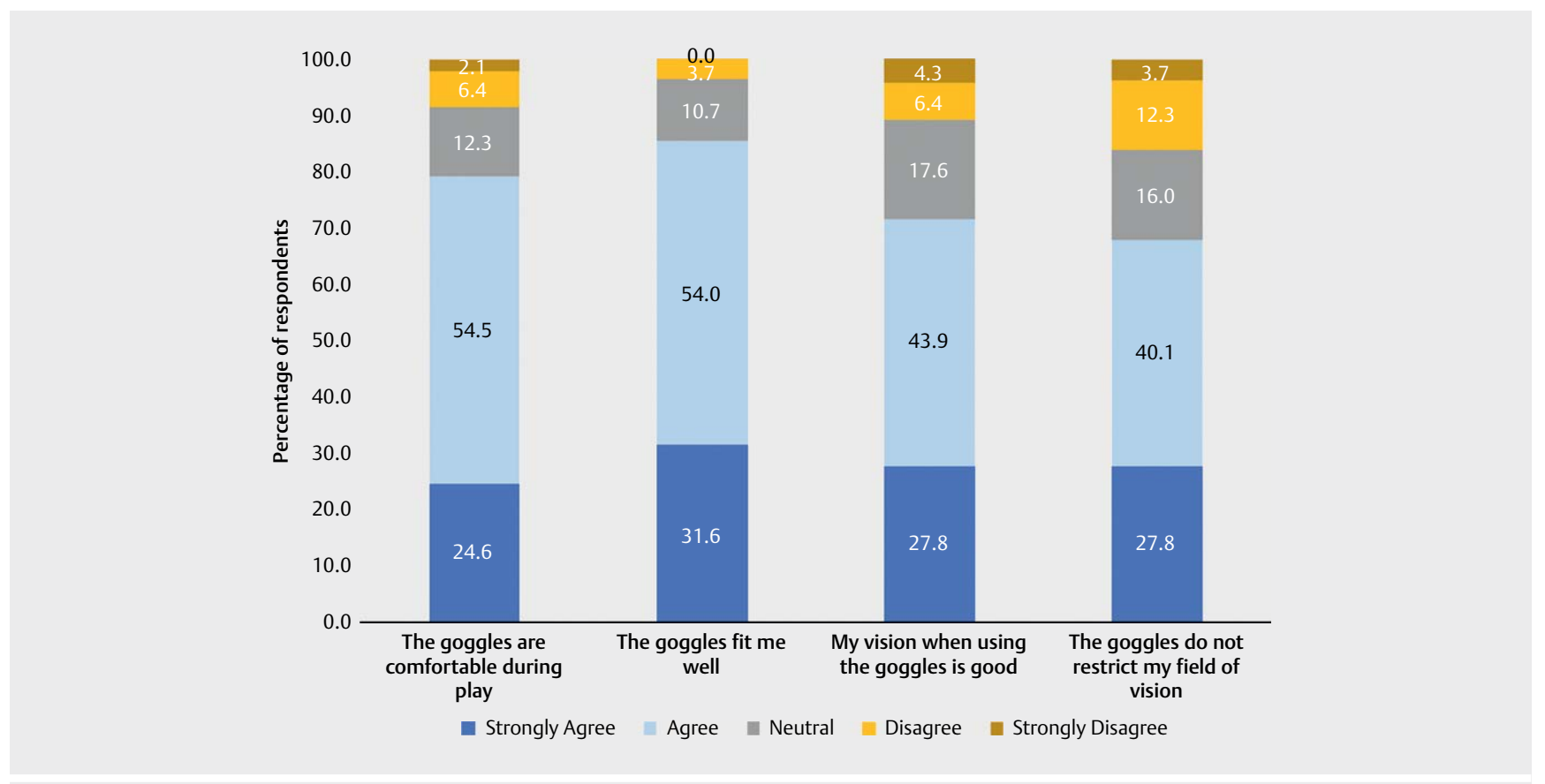

Fig. 3 Responses to statements regarding the comfort, fit, and vision with the goggles. $(n=187)$.

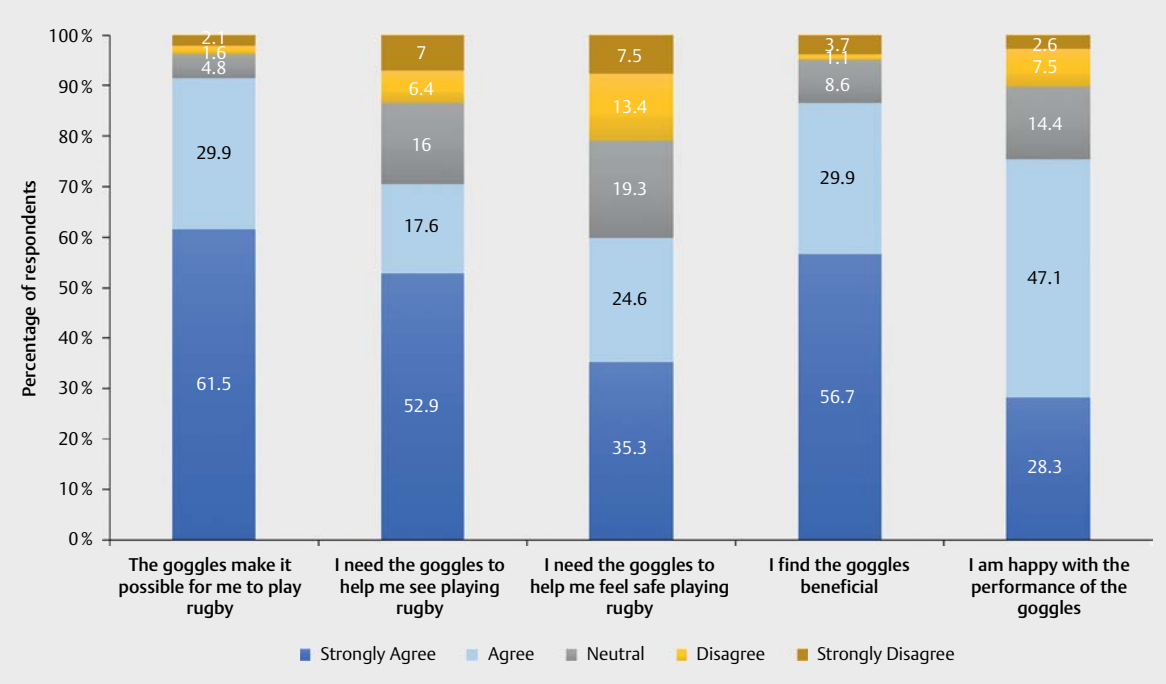

- Fig. 4 Responses to statements regarding participants' satisfaction with the goggles. $(n=187)$.

that the goggles allowed them to play rugby (91\%), to see (71\%), and to feel safe (60\%) playing rugby. A total of $87 \%$ of respondents 'strongly agreed' or 'agreed' that the goggles were beneficial and $75 \%$ were happy with the performance of the goggles. Fifteen (8\%) respondents reported they had stopped wearing the goggles. When asked why, comments included goggles fogging, limits to peripheral vision, and poor comfort/fit. Of these 15 respondents, nine $(66 \%)$ indicated that they 'disagreed' or 'strongly disagreed' with the statement that they were "happy with the performance of the goggles.' Overall, only 1 in 10 respondents disagreed with the statement 'I am happy with the performance of the goggles'.
One of the final questions that respondents were asked was if they thought the rugby goggles should be incorporated into the laws of the game. The vast majority $(93 \%, n=169)$ answered yes. Of those $(7 \%, n=12)$ who responded negatively to this question, none of them had reported that they sustained an injury, and six wore the goggles with the ocular insert. However, the majority (10 of the 12) had reported the goggles fogging up was a big problem or unacceptable. 


\section{Discussion}

For many sports, protective eyewear is available, but this was not the case for Rugby Union. Recent efforts from World Rugby have developed a sports-specific rugby goggle, and this report provides the only information on the wearers' experiences. The response rate (49\%), the duration of goggles wear, and the detailed answers received represent a solid source of information to analyze the performance of the rugby goggles from the wearers' perspective.

There are a number of design issues with rugby goggles. These relate to fogging, foam and strap performance, scratching, vision, and fit, and they should be addressed in future design changes of the goggles to optimize performance and to reduce the risk of injury. Although players acknowledged that these factors may be difficult to address in future versions of the goggles, issues with fogging and the foam padding performance, in particular, were commonly reported and appear to be the most problematic of the issues they raised. In common with other performance specifications for goggles/eyewear, the rugby goggles specification includes a fogging test [20]. However, this test relates to the lens alone and there is no satisfactory accepted test for a complete optical appliance, i. e. the goggle. Better venting or increased anti-fogging surface properties could help in this regard. The trial took place during the rugby season in both hemispheres, but it is worth acknowledging that there were more respondents from Northern hemisphere countries, and so potential fogging issues could be different for rugby played at lower latitudes with differing humidity and ambient temperatures.

Although the injuries reported in this study did not cause lasting effects, any injury associated with the use of the goggles is a source of concern. A common feature of the injuries reported was that the foam padding was not sufficient around the nose to inhibit the edge of the visor of the goggle from contacting the face/nose area. This highlights the importance of the foam/padding issue for manufacturers in the future and respondents made several practical suggestions including the need for better performing foam/ rubberized padding to withstand greater impact. Despite the primary purpose of the goggles being to enable corrective lenses to be worn by those unable to wear contact lenses, rather than for a protective purpose, the impact test cited in the performance specification is not representative of the impacts generated in the sport of rugby, and this could be reviewed to reduce injury risk.

Despite these problems, respondents were generally very positive about the goggles. A total of $91 \%$ of respondents stated that the goggles make it possible for them to play rugby and $87 \%$ stated that they found the goggles beneficial. A total of $75 \%$ were happy with the performance of the goggles. These positive comments underline the value of this initiative by World Rugby to participants who would otherwise be unable to play rugby. Indeed, the evidence from this trial enabled the board of World Rugby to adopt their use into the Laws of the Game on July 1, 2019.

A number of studies have examined the incidence, characteristics, and trends in rugby injuries [21-30], but the data are sparse in relation to eye injuries [31-33]. This is probably due to the fact that non-ocular injuries are extremely common in rugby. A study by MacEwen [31] conducted in two eye casualty units in Glasgow, Scotland, over an 18-month period found that rugby was responsible for $9.8 \%$ of sports-related eye injuries compared to $44.7 \%$ of injuries associated with soccer. A study by Barr et al., [3] also conducted in Scotland, reported no cases of eye injury attributable to rugby over a one-year period. A study from Sussex Eye hospital in England reported $7 \%$ of sports-related injuries to be due to rugby, compared with $24 \%$ for squash, $19 \%$ soccer, $16 \%$ badminton, and $11 \%$ for tennis [34]. Conversely, Pandita \& Merriman [35] followed cases of ocular trauma in an emergency department in New Zealand and found rugby to be the most common cause of sport-related injury. Differences in the proportion of eye injuries associated with rugby presumably reflect the extent to which rugby is played in different countries.

Will the use of goggles in rugby reduce the risk of eye-injury? There are number of reasons why the goggles are unlikely to have an impact on the incidence of eye injuries in rugby. Firstly, the primary purpose of the goggles is to enable corrective lenses to be worn on the field rather than being advocated by World Rugby as protective equipment. The rationale for the introduction of rugby goggles was to grow participation and develop the game without increasing the risks to any player. This non-protective approach is similar to padded headgear and body padding which are non-mandatory and are both restricted to protecting against cuts and abrasions only. Secondly, serious eye injury appears to be quite rare in Rugby Union despite the full-contact nature of the sport. Thus, given the relatively small proportion of players expected to wear the goggles, it is unlikely that it will be possible to demonstrate any significant reduction in eye injures which results from the goggles being worn now that their use has been incorporated into the laws of the game.

Because the need to correct vision with spectacles is common and contact lenses are not worn by $80 \%+$ of spectacle wearers, [36] the new rugby goggles will widen participation for those who need to wear refractive correction and for monocular individuals who cannot risk injury to their remaining eye.

Based upon the results of the Rugby Goggles 2.0 trial, we conclude that goggles represent a largely safe and effective item of equipment for those who, for whatever reason, need eyewear to be able to participate in the sport of rugby.

\section{Acknowledgements}

The authors would like to thank all the players who responded to the questionnaire and took part in the Trial.

Conflict of Interest

The authors declare that they have no conflict of interest.

\section{References}

[1] Leivo T, Haavisto AK, Sahraravand A. Sports-related eye injuries: The current picture. Acta Ophthalmol 2015; 93: 224-231

[2] Ghosh F, Bauer B. Sports-related eye injuries. Acta Ophthalmol Scan 1995; 73: 353-354. doi:10.1111/j.1600-0420.1995.tb00042.x

[3] Barr A, Baines P, Desai P et al. Ocular sports injuries: the current picture. Br J Sports Med 2000; 34: 456-458. doi:10.1136/ bjsm.34.6.456 
[4] MacEwen C], McLatchie GR. Eye injuries in sport. Scott Med J 2010; 55: 22-24

[5] U.S. Consumer Product Safety Commission. Sports and Recreational Eye Injuries. Washington, DC: U.S. Consumer Product Safety Commission; 2000

[6] Cass SP. Ocular injuries in sports. Curr Sports Med Rep 2012; 11: 11-15

[7] Fong SP. Sports-related eye injuries. Med J Aust 1994; 160: 743-747

[8] Dain S]. Sports eyewear protective standards. Clin Exp Optom 2016; 99: 4-23

[9] Kriz PK, David Zurakowski D et al. Eye protection and risk of eye injuries in high school field hockey. Pediatrics 2015;136: 521-527. doi:10.1542/peds.2015-0216

[10] Napier SM, Baker RS, Sanford DG et al. Eye injuries in athletics and recreation. Surv Ophthalmol 1996; 4: 229-244

[11] Eime R, Finch C, Wolfe R et al. The effectiveness of a squash eyewear promotion strategy. Br J Sports Med 2005; 39: 681-685

[12] Williams KM, Verhoeven VJ, Cumberland P et al. Prevalence of refractive error in Europe: The European Eye Epidemiology $(E(3))$ Consortium. Eur J Epidemiol 2015; 30: 305-315

[13] O'Donoghue L, McClelland JF, Logan NS et al. Refractive error and visual impairment in school children in Northern Ireland. $\mathrm{Br}$ ] Ophthalmol 2010; 94: 1155-1159

[14] World Rugby Player numbers; https://www.world.rugby/development/ player-numbers accessed March 20, 2019

[15] World Rugby Laws; https://laws.worldrugby.org/?law = 4 accessed July 19, 2019

[16] Rodriguez JO, Lavina AM, Agarwal A. Prevention and treatment of common eye injuries in sports. Am Fam Physician 2003; 67: $1481-1488$

[17] World Rugby Player Welfare Rugby Goggle Performance Specification; https://playerwelfare.worldrugby.org/players-equipment-goggles accessed July 19, 2019

[18] World Rugby Player Welfare Rugby Goggle Trial 2.0 Report; https:// playerwelfare. worldrugby.org/?documentid $=205$

[19] Harriss DJ, Macsween A, Atkinson G. Standards for ethics in sport and exercise science research: 2020 update. Int J Sports Med 2019; 40: 813-817

[20] BS EN 168:2002 Personal eye-protection. Non-optical test methods; https://shop.bsigroup.com/ProductDetail/?pid=000000000030036280

[21] Lee A], Garrayway WM. Epidemiological comparison of injuries in school and senior club rugby. Br J Sports Med 1996; 30: 213-217
[22] Bird YN, Waller AE, Marshall SW et al. The New Zealand rugby injury and performance project: V. Epidemiology of a season of rugby injury. Br J Sports Med 1998; 32: 319-325

[23] MacQueen AE, Dexter WW. Injury trends and prevention in rugby union football. Curr Sports Med Rep 2010; 9: 139-143. doi:10.1249/ JSR.0b013e3181df124c

[24] Schick DM, Molloy MG, Wiley JP. Injuries during the 2006 women's rugby world cup. Br J Sports Med 2008; 42: 227-451

[25] Williams S, Trewartha G, Kemp S et al. A meta-analysis of injuries in senior men's professional rugby union. Sports Med 2013; 43: 1043-1055

[26] Gardner A], Iverson GL, Williams WH et al. A systematic review and meta-analysis of concussion in rugby union. Sports Med 2014; 44: 1717-1731

[27] Freitag A, Kirkwood G, Scharer S et al. Systematic review of rugby injuries in children and adolescents under 21 years. $\mathrm{Br}$ J Sports Med 2015; 49: 511-519

[28] Brown JC, Verhagen E, Knol D et al. The effectiveness of nationwide BokSmart rugby injury prevention program on catastrophic injury rates. Scand J Med Sci Sports 2016; 26: 221-225

[29] Fuller CW, Taylor A, Kemp SP et al. Rugby World Cup 2015: World Rugby injury surveillance study. Br J Sports Med 2017; 51: 51-57. doi:10.1136/bjsports-2016-096275

[30] Yeomans C, Kenny IC, Cahalan R et al. The incidence of injury in amateur male Rugby Union: A systematic review and meta-analysis. Sports Med 2018; 48: 837-848. doi:10.1007/s40279-017-0838-4

[31] MacEwen C]. Sport associated eye injury: A casualty department survey. Br J Ophthalmol 1987; 71: 701-705

[32] Lawson JS, Rotem T, Wilson SF. Catastrophic injuries to the eyes and testicles in footballers. Med J Aust 1995; 163: 242-244

[33] Carson JD, Roberts MA, White AL. The epidemiology of women's rugby injuries. Clin J Sport Med 1999; 9: 75-78

[34] Gregory PTS. Sussex eye hospital sports injuries. Br J Ophthalmol 1986; 70: 748-750

[35] Pandita A, Merriman M. Ocular trauma epidemiology: 10-year retrospective study. N Z Med J 2012; 125: 61-69

[36] Euromcontact. A Comparison of European Soft Contact Lens and Lens Care Markets in 2017; https://euromcontact.org/2018/05/07/ euromcontact-releases-2017-market-data-report/ accessed August 9, 2019 